\title{
The Design and Implementation Accounting Laboratory Management System Based on SOA
}

\author{
Zhengbo $\mathrm{Li}^{1 \text {, a }}$ \\ ${ }^{1}$ School of Economic Management, Beihua University, Jilin 132013, China. \\ a zhengbo_li@126.com
}

Keywords: Accounting laboratory management, SOA, LIMS.

\begin{abstract}
According to current situation of accounting laboratory management and development of computer technology, the SOA(Service Oriented Architecture)based on the open standards for accounting laboratory management is designed for intelligent management. The system combines the technology of LIMS(Laboratory Information Management System) and Mobile Internet. Tests show that the system meets the needs of accounting laboratories and reaches the commercial level and achieves automatically management of information as well as intelligent monitoring.
\end{abstract}

\section{Introduction}

The current level of domestic colleges and universities accounting for each laboratory information management generally low. Accounting required laboratory equipment from requisitions, purchase, installation, maintenance and repair, scrap and other process and associated information is recorded and saved in the form file. The event management changes, accounting laboratory equipment maintenance, relocation and other special circumstances, a variety of laboratory equipment accounting information can not be reflected in the log file, then often require re-registration of all accounting laboratory verification. In addition, the accounting for frequent laboratory equipment maintenance, spare parts replacement, when the state-owned statistics, accounting for failing to implement laboratory information arising from the heavy work of the management and staff of colleges and universities to form a huge burden.

Information management is information from one or more sources to collect and manage distribution. Management is planning to proceed in terms of structure, process, evaluate, organize and control information reporting activities to meet the client's goals, so that enterprises function in the information ways.

Throughout the 1970s, information management is still largely confined to the form of documents, including documents and files to maintain the life-cycle management, as well as other media and paper records. As information technology from the 1970s, information management work will have a new development, began to include the maintenance of the data field, information is stored as electronic steering technology. Information management is no longer a simple task that anyone can complete. Technical and theoretical support for information management involves becomes necessary. In the late 1990s, the information often spread to computer networks and other electronic devices, network management personnel in a sense become the information manager. The latest tools, information management as a new tool has become a powerful resource for many organizations. In short, the information management needs of the organization, retrieval, access, protection and maintenance information, and it is the practice and management of data are closely related.

This design of computer laboratory management system combines accounting management accounting status of domestic colleges and universities laboratory, learn the advanced laboratory information management accounting concepts, after a long period of fieldwork, laboratory management accounting to meet the basic needs of the general colleges and universities. Flexible design of the system, as the fundamental and practical design ideas, computer lab device management accounting for the main functions, personnel management for the auxiliary functions. The system will improve largely behind some of the current status of college accounting laboratory management, improve the efficiency of equipment management accounting laboratory staff, reduce office costs and 
the ability of school-related personnel, state-owned assets management, procurement office and other accounting laboratory relevant departments to provide a variety of real-time information needed to improve the campus overall level of information management.

The system uses SOA service-oriented architecture, the main purpose is to design a computer lab device management accounting and personnel management overall external call to provide a unified interface, comprehensive information management throughout the campus.

\section{Laboratory Information Management Systems Engineering LIMS}

Laboratory Information Management System LIM S has so far developed more than three decades, since the past ten years, information technology, Internet technology, the rapid development of various technology platforms for LIMS has played a significant role in promoting. The current LIM S content is no longer managed by a simple functional equipment management, personnel management, sample management and print out reports, etc., with advances in software engineering technology and industry standards, coupled with Internet technology infiltrated into all sectors every corner of the application LIM S has reached an unprecedented height in the last few decades.

The first generation of LIM S appeared in the late seventies, when the majority of the laboratories LIM S software development service providers technical support or rely on the technical strength of the unit and technical personnel, according to the laboratory features, tailored set of management systems, do not have common characteristics. Because of technical ability, funding and other issues, such as multi-management system has insufficient capabilities, system upgrade maintenance difficulties, poor flexibility circumstances. Later, with the development of the system into commercial development, the gradual disappearance of the original LIMS from various organizations and enterprises, while domestic large and because the difference between the idea of the gap between the international level, the commercialization of LIMS development has not been widely supported and recognized.

Commercialization LIMS, namely the second generation appeared in the eighties, this type of system is based on client / server architecture to solve the many problems that exist in the first-generation LIMS. For example, users can realize the majority of the demand for change in laboratory support, system upgrades and maintenance simple and convenient system utilization is improved. However, there are still some difficult to reconcile the contradictions, such as commercial LIMS system is a general-purpose, after the installation of the system requires the user function of the particular needs of each laboratory to increase coding, which requires programmers to take into account at the same time LIMS system administrator. The nature of the laboratory are diverse, many computer programmers are born, we can not understand the operational mechanisms of biological laboratories, which brings difficulties to the coding system. In addition, the liquidity of computer programmers is large, frequent maintenance work because the system was designed and programmers leave standstill. For these reasons, no professional computer staff to LIM S can manage and maintain the largest demand.

\section{Related technical system design}

Firstly, the system management mode, in order to determine the overall SOA architecture as a framework for computer laboratory management system; after details of the type of SOA architecture and the architecture, features and advantages; Web Service in XML, SOAP, WSDL and UDDI as the SOA architecture mainly technology.

In the design most laboratory management system, developers and more emphasis on the study of the system function, development platforms and technologies, system components, and easy to overlook the overall system architecture. The overall system architecture from the concrete manifestation point of view, much of the system functional requirements involved, but it can affect the performance requirements of usability lab management systems and the like. Many existing laboratory management system software and hardware configuration of a wide variety, even within 
the same school, due to differences in sector management rights, are each formed station situation, a different type of system platforms, software development, infrastructure, cross-cutting and their system is relatively independent, these big obstacle for digital campus is currently promoting the formation, therefore, focus of this paper is to apply the design direction of SOA service-oriented architecture, will be present in the dispersion campus, independent laboratory management unified service up, play the greatest degree of efficiency of the system.

Use of resources SOA service-oriented design thinking to design and develop computer laboratory management system, optimize the structure of the system can maximize and improve the management and efficiency of the computer lab, the effective use of the campus and campus information technology lay a solid foundation.

Laboratory management generally be divided into centralized management and decentralized management modes. Decentralization is a way of many colleges and universities are currently used, laboratory construction is relatively dispersed, their development and construction, in the management of multi-pronged easy to form, for administration, the increase in the number of repetitive work, heavy administrative burden. Centralized management is a multiple laboratories in accordance with certain rules, unified set of services and interfaces to effectively manage scattered in various laboratory platform, application software systems, hardware devices, network connections. Centralized management can focus on the greatest degree of all resources, lower construction costs, and the system high security, ease of management.

1 , the presentation layer. The presentation layer provides the application's user interface (Un. Typically, this involves Windows Forms-based smart client interaction and interactive browser-based ASP.NET technology. Application consists of a series of the form (p) interaction with the user each form contains a number of input fields to display output from the lower level and collect the user to achieve a form of user interface, there are two types of components: user interface components and user interface process components.

2, the business layer. Large enterprise applications are typically around the concept of business processes and business components. These concepts are solved by a number of service layer components, entities, agents, and interfaces. Business layer implement business functionality applications usually consist of many components, using one or more .NET programming language.

3, the data layer. Most business applications need to access data stored in corporate databases, the most common is a relational database. Data access components in the data layer is responsible for displaying the data stored in the database service layer. The main uses .NET technology ADO.NET.

\section{SOA Design}

Computer Lab Management System is based on soa service-oriented architecture, we need to clear the system and service design principles, principles of operation and then refine the service, to build the core system modules to form the overall system architecture.

Computer Lab Management System is designed to function modules related laboratory management and effective integration in the overall system more responsive to the School of Environment, more flexible and efficient management, here are a few basic principles of system design to follow:

1 , the system integrity. In the computer laboratory management system, each management unit independent both play their respective functions, they can be interrelated. From equipment management, laboratory information management, system management aspects complement each other to achieve a comprehensive School computer lab as a whole.

2 , the system function integration. When the system design, integration, two aspects proceed from information integration and process, the contact system is not very tightly integrated functional units play a role. Information integration can help to transfer information within the system timely, accurate information in the transfer process to ensure data integrity, improve the efficiency of the system, to facilitate the management of personnel and equipment. Process Integration will manage the process closely, so that business-related workflow management system, the data flow is valid 
interconnection, sharing of data between transactional systems and resources. The biggest advantage is the functional integration reduces system business in excess part of the workflow, the order of transmission of information between modules to adjust and optimize laboratory workflow.

3 , system standardization. For business processes and data systems designed to operate in strict accordance with the established standards; system design, optimize business processes to achieve the highest efficiency device management and personnel management; For multiple lab device management, unified according to standard classification, and functional expansion of the system to reserve a standard interface.

\section{Conclusion}

After extensive research laboratory management theory at home and abroad, by analyzing the status of the domestic computer lab of university management, basic business process, we decided to adopt SOA Service Oriented Architecture design system, and to do system-related key technologies needed, such as Web Service, etc. in-depth research, combined with ASP.NET and SQL Serve: database technology, equipment management, personnel management, computer laboratory management system, laboratory project settings and system management functions.

This paper work include:

1 for laboratory management mode, in-depth understanding of SOA and Web Service technologies for building service-oriented architecture laboratory management system basis.

2 , the computer lab of the basic business processes to make detailed needs analysis, design the basic building blocks of the system and the definition of reasonable service interface.

3 , in accordance with the principles of SOA design principles and service operations, services for system modeling, decomposition and public service, the service interface definition, service composition and service registration.

4, to determine the overall system function module, use and development of language, database, and Web Service technology, complete system function performance, load and design rights, and the system were tested.

Using SOA architecture design of the system architecture, the system can make the function expansion, database updates and links easier, while facilitating the college of information technology, it is more convenient to access the campus network information and provide a good interface to other systems.

\section{References}

[1] Bai Zhiqing, Zhang silver laboratory information management system (LIMS) Summary field. Information Development and Economy, 2007,17 (12) 36-39

[2] Discussion on Chen Yun red room management of institutions of higher learning in China Water Transport (Academic Edition), 2006, 10 (8): 13-16

[3] Yang Jasper Design Laboratory NMS Guangxi Quality Supervision, Review, 2008, 10 (1): 39-40

[4] Chenpei Min Development of Computer Laboratory Management System for Scientific and Technological Advice Review, 2007, 16 (22): 178.

[5] Jiang Ping, Wang Zheng. Design and implementation of Open Computer Laboratory Management System to monitor computer and Modernization, 2007,47-49

[6] Yang Taibing laboratory information management system (LIMS) About Beijing: Beijing Science and Technology Press, 2009; 